\title{
Update of the morbidity experience of employees potentially exposed to chlorpyrifos
}

\author{
Carol J Burns, Janice B Cartmill, Brian S Powers, Marcia K Lee
}

\begin{abstract}
Objectives-Chlorpyrifos, an organophosphate ingredient of several important insecticides, has been manufactured at The Dow Chemical Company for 25 years. A previous morbidity study among employees of The Dow Chemical Company found no increased prevalence of illness or symptoms among employees potentially exposed to chlorpyrifos from 1977 to 1985 compared with matched controls. The purpose of the current study was to update the original study to 1994 , thereby increasing the statistical power.

Methods-In the present study, 496 potentially exposed subjects were identified and matched for age, race, sex, pay, and year of hire to 911 control subjects. Morbidity data were abstracted from company medical records.

Results-The prevalence of peripheral neuropathy was not significantly increased among this group of employees potentially exposed to chlorpyrifos. Significantly increased prevalence odds ratios were identified for five diagnostic categories: diseases of the ear and mastoid process; acute respiratory infections; other diseases of the respiratory system; general symptoms, signs, and ill defined conditions; and symptoms, signs, and ill defined conditions involving the digestive system. There was a strong association of diagnosis with duration of observation period, indicating that the exposed workers were more likely than unexposed workers to have a diagnosis abstracted from the company medical records due to their longer mean period of follow up. Analyses by exposure classification and mean plasma cholinesterase activity did not show a dose response.
\end{abstract}

Conclusions-These data do not support a cause and effect relation of the diagnoses mentioned and exposure to chlorpyrifos.

The Dow Chemical

Company, 1803

Building, Midland, MI

48674, USA

C J Burns

J B Cartmill

B S Powers

M K Lee

Correspondence to: Dr Carol J Burns, The Dow Chemical Company, 1803 Building, Midland,

MI 48674, USA.

Accepted 10 July 1997 demiological studies have examined chronic neurological effects after acute poisoning with organophosphates. ${ }^{9-11}$ These studies, however, were not specific to chlorpyrifos.

Brenner et al examined the morbidity experience of Dow employees occupationally exposed to chlorpyrifos during its manufacture and formulation from 1977 to $1985 .^{12}$ No significant differences in illness or symptom prevalence were found between the potentially exposed and unexposed groups. The authors noted that the small sample size available for the study limited the statistical power. Consequently, the current update was conducted to expand the observation period up to 1994 .

\section{Materials and methods}

The current methods closely paralleled those used in the original investigation. Potentially exposed employees were defined as any full time employee of The Dow Chemical Company who worked in the manufacture or formulation of chlorpyrifos between 1 January 1977 and 31 December 1994. Two unexposed employees (controls) were sought for each exposed subject (cases) matching for age (within 7.5 years), race, sex, year of hire (within 7.5 years), and pay (hourly, salary exempt, or salary non-exempt). Each control must have been actively employed in Midland at the time the exposed subject qualified for inclusion in the study. Those working in other departments with potential exposure to chlorpyrifos were excluded from consideration as controls. People who had previously received cholinesterase testing, suggesting exposure to chlorpyrifos or other cholinesterase inhibitors, were also excluded from the control group.

Where possible, the original cohort of exposed and unexposed workers was retained. Of the 335 original controls, 56 were excluded from this update because they had undergone cholinesterase testing, were never full time employees, or had not worked in Midland during the observation period of their matched case. Twelve controls were now considered to be eligible cases for whom matched controls were selected. Of the 175 original cases, six were excluded because they no longer had an eligible control and additional controls could not be found who met the matching criteria. The resulting study cohort to 1994 comprised 496 potentially exposed subjects and 911 control subjects.

The study observation period for the cases was defined as the period employed in chlorpyrifos manufacturing or formulation, plus 30 days. Where possible, the observation period for the controls was identical to that of their 
Table 1 Summary of the exposure groups and the corresponding classification criteria

\begin{tabular}{|c|c|}
\hline $\begin{array}{l}\text { Exposure } \\
\text { group }\end{array}$ & Classification criteria \\
\hline High & $\begin{array}{l}\text { Potential average airborne exposures to chlorpyrifos } \geqslant 0.2 \mathrm{mg} / \mathrm{m}^{3} \text {, or high } \\
\text { potential dermal exposure to chlorpyrifos }\end{array}$ \\
\hline Moderate & $\begin{array}{l}\text { Potential average airborne exposures to chlorpyrifos }<0.2 \mathrm{mg} / \mathrm{m}^{3} \text { and } \geqslant 0.03 \\
\mathrm{mg} / \mathrm{m}^{3} \text {, or moderate potential dermal exposure to chlorpyrifos }\end{array}$ \\
\hline Low & $\begin{array}{l}\text { Potential average airborne exposures to chlorpyrifos }<0.03 \mathrm{mg} / \mathrm{m}^{3} \text { and } \geqslant 0.01 \\
\mathrm{mg} / \mathrm{m}^{3} \text {, or low potential dermal exposure to chlorpyrifos }\end{array}$ \\
\hline Negligible & $\begin{array}{l}\text { Potential average airborne exposures to chlorpyrifos that were below the } \\
\text { sampling limit of measurement and }<0.01 \mathrm{mg} / \mathrm{m}^{3} \text {, or negligible potential } \\
\text { dermal exposure to chlorpyrifos }\end{array}$ \\
\hline
\end{tabular}

Note: The 1996 American Conference of Governmental Industrial Hygienist's recommended threshold limit value (TLV) for chlorpyrifos is $0.2 \mathrm{mg} / \mathrm{m}^{3}$ for an 8 hour time weighted average. The TLV for chlorpyrifos has a skin notation which indicates that it may be absorbed through the skin in harmful amounts. dermal exposure. The exposure to chlorpyrifos groups were defined as high, moderate, low, or negligible for each job classification (table 1). For each exposed subject, a detailed work history was reviewed. With the classification criteria, each job was assigned its corresponding exposure level. To maximise the impact of high exposures to chlorpyrifos the following weighting was used: high $=9$; moderate $=6$; low $=3$; negligible $=1$. The exposure weighting for each job was multiplied by the number of days employed in the job assignment. The cumulative exposure weighting for each employee was determined by dividing the sum of the weightings in all assignments by the entire number of days worked in the plants of interest. The employee's overall exposure weighting was then converted to the corresponding categorical ranking (high: $\geqslant 7.5$; moderate: $\geqslant 4.5$ to $<7.5$; low: $\geqslant 2$ to $<4.5$; and negligible: $<2$ ). the international classification of diseases ninth revision (ICD-9) by a nurse nosologist. All previously recorded medical information was retained and recorded only for newly identified subjects and original study subjects for whom the observation period extended beyond 1985. To maintain consistency with the original study, only the first observation of any disease or symptom was recorded for the following main diagnostic categories: the nervous system (ICD-9 320-389), the respiratory system (ICD-9 460-519), the digestive system (ICD-9 520-579), the kidney (ICD-9 580 630), and general symptoms (ICD-9 780799).

The diseases recorded in the original study were limited to selected ICD-9 codes considered to be relevant to chlorpyrifos exposure. For example, disorders of the eye and the ear were not included in the original study. Specific illnesses - such as the common cold and acute tonsillitis-were also excluded. As a departure from the original design, all diagnoses after 1985, which were coded within the five ranges already broadly defined, were included in this update. However, medical data of the original subjects from 1977 to 1985 were not reviewed again. Although the data collection methods were more inclusive than those of the first investigation, it was thought that the quality of the data would be higher if the abstractors were not required to judge whether a specific diagnosis should or should not be recorded.

Uses of tobacco, alcohol, and cholinergic medications, including cholinesterase inhibitors, were also obtained from medical documents and computerised records. Self reported paraesthesia was obtained through computerised data from the questionnaire issued during the periodic medical surveillance examination (Have you had persistent numbness or tingling of hands or feet?). Although not recorded as part of the original investigation, paraesthesia data were available from 1982 to the present. As a quality assurance measure, a physician reviewed a $10 \%$ sample of the abstractors' work and ascertained that the data abstracted were complete and valid.

ASSESSMENT OF EXPOSURE

Exposure was categorised from available airborne monitoring data and the potential for

\section{STATISTICAL ANALYSIS}

The measure of association between exposure and disease was the prevalence odds ratio (OR), which was calculated as the ratio of the of disease among the unexposed. The MantelHaenszel method was used to combine data across strata to control for potential confounding. ${ }^{13}$ Unconditional logistic regression was used to evaluate potential dose relations with exposure level and mean plasma cholinesterase activity for diseases with significantly increased prevalences among the cases while controlling for the matching variables.

All Dow employees with potential exposure to chlorpyrifos or other cholinesterase inhibitors are required to have monthly cholinesterase tests. A percentage change from the pre-exposure baseline was calculated for each reading. A mean and a minimum (peak) percentage change in plasma cholinesterase were calculated for each case. A zero percentage change from baseline was defined as $100 \%$ activity. Consequently, a 30\% increase would reflect a $130 \%$ activity and a $30 \%$ depression would reflect a $70 \%$ activity. The cholinesterase values were categorised into three groups: $\leqslant 50 \%$ activity (inhibition from baseline), $50 \%$ to $90 \%$ activity, and $\geqslant 90 \%$ activity.

The number of medical surveillance visits in which the subjects participated was considered a potential confounder. Computerised records were only available since 1982 . All subjects for whom observation periods did not extend to or beyond 1982 were excluded from analyses with medical surveillance data as were all coded diagnoses which occurred before 1982. The number of visits per subject ranged from none to eight. Stratified analyses were conducted with the following strata: none, one, two, and three or more visits.

\section{Results}

Table 2 shows that comparable matching between cases and controls was achieved. However, only one matched control could be identified for 81 cases. Tobacco and alcohol use were also comparable between cases and controls although no attempt was made to odds of disease among the exposed to the odds 
Table 2 Distribution of exposed and control subjects by matching variables and potential confounders

\begin{tabular}{|c|c|c|c|c|}
\hline & \multicolumn{2}{|c|}{ Exposed group $(n=496)$} & \multicolumn{2}{|c|}{ Control group $(n=911)$} \\
\hline & Date & $n(\%)$ & Date & $n(\%)$ \\
\hline Mean (SD) birth year & 1952 & & 1951 & \\
\hline Range & $(1915$ & & $(191$ & \\
\hline Mean (SD) hire year & 1977 & & 1976 & \\
\hline Range & $(1935$ & & $(193$ & \\
\hline \multicolumn{5}{|l|}{ Race: } \\
\hline White, Hispanic, Asian, American Indian & & $471(94.96)$ & & $873(95.83)$ \\
\hline Black & & $25(5.04)$ & & $38(4.17)$ \\
\hline \multicolumn{5}{|l|}{ Sex: } \\
\hline Men & & $423(85.28)$ & & $795(87.27)$ \\
\hline Women & & $73(14.72)$ & & $116(12.73)$ \\
\hline \multicolumn{5}{|l|}{ Pay status: } \\
\hline Hourly & & $365(73.59)$ & & $651(71.46)$ \\
\hline Non-exempt & & $25(5.04)$ & & $46(5.05)$ \\
\hline Exempt & & $89(17.94)$ & & $159(17.45)$ \\
\hline Unknown & & $17(3.43)$ & & $55(6.04)$ \\
\hline Ever smoked tobacco ${ }^{\star}$ & & $255(51.83)$ & & $452(50.28)$ \\
\hline Current smokers $\dagger$ & & $89(23.18)$ & & $191(26.16)$ \\
\hline Problem drinker (as noted by physician) & & $17(3.45)$ & & $32(3.52)$ \\
\hline \multicolumn{5}{|l|}{ Self reported number of drinks per day: } \\
\hline $0-1$ & & $351(77.48)$ & & $636(77.37)$ \\
\hline $1-2$ & & $78(17.22)$ & & $139(16.91)$ \\
\hline$\geqslant 3$ & & $24(5.30)$ & & $47(5.72)$ \\
\hline
\end{tabular}

^Data missing for four cases and 12 controls.

†Data missing for 112 cases and 181 controls.

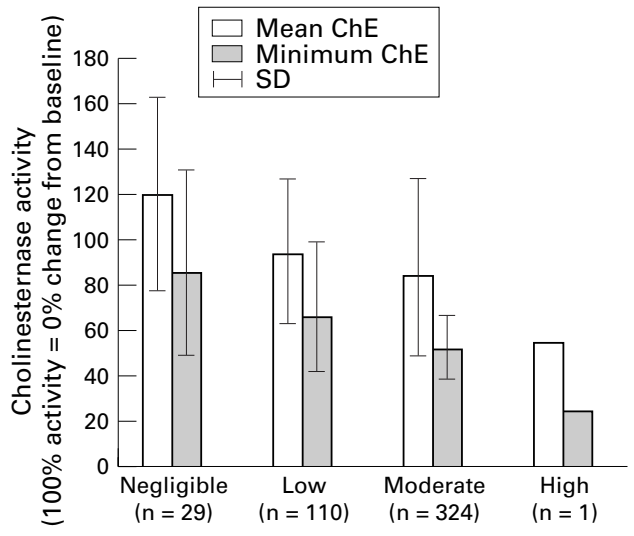

Cholinesterase activity by level of exposure (cholinesterase values were missing for 32 cases).

match on these potential confounders. However, self reported use of alcohol did not correlate with physicians' comments within the medical records regarding problem drinking. Only four subjects were recorded as using cholinergic medications. Use of alcohol and cholinergic medications were not considered in the analysis as potential confounders due to lack of agreement and small numbers. Stratified analyses by smoking did not show confounding and are not presented in this report.

Based on the industrial hygiene data, most cases were classified as having potential for moderate exposure $(n=345)$. Only one person was classified in the high potential exposure category. As this subject had no medical diagnoses recorded, the analyses with exposure level excluded this highest category. The validity of the exposure categories is supported by the rough correlation between the plasma cholinesterase values and potential exposure levels. However, the SDs across people are substantial (figure).

NERVOUS SYSTEM

A smaller percentage of cases than controls reported experiencing tingling or numbness in their hands or feet (OR $0.86,95 \%$ confidence interval $(95 \% \mathrm{CI}) 0.50$ to 1.48$)$ on their health surveillance questionnaire (data not shown). This was unchanged after controlling for tobacco use, alcohol consumption, and the number of times this question was asked.

Diagnoses involving the nervous system and sense organs were more prevalent among the cases than the controls (OR 1.58, 95\% CI 1.19 to 2.10 , table 3 ). This increase can be traced to the significantly higher prevalence of diseases of the ear (OR 1.81, 95\% CI 1.29 to 2.54). The study subjects within this category experienced infections of the outer ear, impacted ear wax, diseases and infections of the middle ear, and unspecified hearing loss. Analyses by exposure level and mean percentage change in plasma cholinesterase for this specific category showed an inverse dose response. With the lowest, minimum cholinesterase activity, the highest OR occurred in the category with the least activity (table 4). The 16 illnesses reported in the peripheral nervous system category were primarily carpal tunnel syndrome. There was no significant increase of peripheral neuropathy among the cases.

\section{RESPIRATORY SYSTEM}

Infectious respiratory illnesses and symptoms were also recorded significantly more often among the cases than controls (table 3 ). This increase was due to the higher prevalence of acute respiratory infections (OR $1.49,95 \%$ CI 1.08 to 2.05 ) and other diseases of the respiratory system (OR $2.80,95 \%$ CI 1.18 to 6.65 ). Diagnoses recorded in this population within the category of acute respiratory infections are sinusitis, pharyngitis, laryngitis, bronchitis, and the common cold. These symptoms or illnesses were seen significantly more often in the male subjects and showed no dose response by exposure category or mean cholinesterase activity. The highest $\mathrm{OR}$ for minimum cholinesterase activity was found in the category with the least activity (table 4). Other diseases of the respiratory system were found 
Table 3 Prevalent crude OR for all disease conditions

\begin{tabular}{|c|c|c|c|c|}
\hline Disease category (ICD-9) & $\begin{array}{l}\text { Exposed group } \\
(n=496)\end{array}$ & $\begin{array}{l}\text { Control group } \\
(n=911)\end{array}$ & $O R$ & $95 \% \mathrm{Cl}$ \\
\hline Nervous system and sense organs $(320-89)$ : & 101 & 127 & 1.58 & 1.19 to 2.10 \\
\hline Other disorders of the central nervous system (340-349) & 13 & 21 & 1.14 & 0.57 to 2.30 \\
\hline Peripheral nervous system $(350-59)$ & 8 & 8 & 1.85 & 0.70 to 4.89 \\
\hline Disorders of the eye and adnexa (360-379) & 30 & 48 & 1.16 & 0.72 to 1.85 \\
\hline Diseases of the ear and mastoid process $(380-389)$ & 72 & 78 & 1.81 & 1.29 to 2.54 \\
\hline Respiratory system (460-519): & 137 & 196 & 1.39 & 1.08 to 1.79 \\
\hline Acute respiratory infections $(460-66)$ & 77 & 100 & 1.49 & 1.08 to 2.05 \\
\hline Other disease of upper respiratory tract $(470-78)$ & 60 & 104 & 1.07 & 0.76 to 1.50 \\
\hline Chronic obstructive pulmonary disease and allied conditions (490-96) & 47 & 63 & 1.41 & 0.95 to 2.09 \\
\hline Pneumoconioses and other lung diseases due to external agents (500-08) & 2 & 7 & 0.52 & 0.11 to 2.46 \\
\hline Other diseases of respiratory system $(510-19)$ & 12 & 8 & 2.80 & 1.18 to 6.65 \\
\hline Digestive system (520-79): & 72 & 109 & 1.25 & 0.91 to 1.72 \\
\hline Liver (570-73) & 3 & 0 & - & - \\
\hline Kidney $(580-630)$ & 13 & 15 & 1.61 & 0.76 to 3.39 \\
\hline Symptoms, signs, and ill defined conditions (780-99): & 192 & 306 & 1.25 & 0.99 to 1.57 \\
\hline General (780) & 58 & 68 & 1.64 & 1.14 to 2.37 \\
\hline Involving nervous and musculoskeletal system (781) & 2 & 2 & 1.84 & 0.27 to 12.73 \\
\hline Involving skin and other integumentary tissue (782) & 52 & 74 & 1.33 & 0.91 to 1.92 \\
\hline Involving head and neck (784) & 37 & 63 & 1.09 & 0.71 to 1.65 \\
\hline Involving respiratory system and other chest symptoms (786) & 61 & 105 & 1.08 & 0.77 to 1.51 \\
\hline Involving digestive system (787) & 42 & 48 & 1.66 & 1.09 to 2.55 \\
\hline Non-specific abnormal findings $(790-96)$ & 98 & 164 & 1.12 & 0.85 to 1.48 \\
\hline
\end{tabular}

Subjects could contribute to more than one diagnostic subcategory but only one observation per subject was counted in the major categories.

Therefore the sum of subjects within the subcategories will not equal the total in the major categories.

Table 4 Prevalent ORs by exposure level and plasma cholinesterase (ChE $E^{\star}$ activity as \% of pre-exposure baseline

\begin{tabular}{|c|c|c|c|c|c|c|c|c|}
\hline \multirow[b]{2}{*}{ Disease category (ICD-9) } & \multicolumn{2}{|c|}{$\begin{array}{l}\text { Diseases of the ear and } \\
\text { mastoid process }\end{array}$} & \multicolumn{2}{|c|}{ Acute respiratory infections } & \multicolumn{2}{|c|}{$\begin{array}{l}\text { General symptoms, signs and ill } \\
\text { defined conditions }\end{array}$} & \multicolumn{2}{|c|}{$\begin{array}{l}\text { Ill defined conditions of the } \\
\text { digestive system }\end{array}$} \\
\hline & $O R$ & $95 \% C I$ & $O R$ & $95 \% C I$ & $O R$ & $95 \% C I$ & $O R$ & $95 \% C I$ \\
\hline \multicolumn{9}{|l|}{ Exposure level: } \\
\hline Negligible $(n=29)$ & 3.21 & 1.19 to 8.71 & 1.92 & 0.62 to 5.98 & 1.86 & 0.51 to 6.80 & 10.85 & 2.95 to 40.00 \\
\hline Low $(n=121)$ & 2.69 & 1.52 to 4.75 & 1.12 & 0.58 to 2.19 & 1.91 & 0.97 to 3.76 & 1.28 & 0.45 to 3.59 \\
\hline Moderate $(\mathrm{n}=345)$ & 1.62 & 1.08 to 2.42 & 1.55 & 1.08 to 2.21 & 1.54 & 1.01 to 2.35 & 1.47 & 0.90 to 2.40 \\
\hline \multicolumn{9}{|l|}{ Mean ChE activity (\%): } \\
\hline$\geqslant 90(\mathrm{n}=169)$ & 3.65 & 2.36 to 5.63 & 2.26 & 1.46 to 3.50 & 2.34 & 1.42 to 3.87 & 2.21 & 1.18 to 4.15 \\
\hline $90-50(n=261)$ & 1.42 & 0.90 to 2.25 & 1.21 & 0.80 to 1.82 & 1.12 & 0.68 to 1.86 & 1.26 & 0.71 to 2.22 \\
\hline$\leqslant 50(\mathrm{n}=34)$ & 0.30 & 0.04 to 2.19 & 1.39 & 0.5 to 3.68 & 1.26 & 0.37 to 4.24 & 0.66 & 0.09 to 5.01 \\
\hline \multicolumn{9}{|c|}{ Minimum ChE activity (\%): } \\
\hline$\geqslant 90(\mathrm{n}=42)$ & 1.61 & 0.61 to 4.25 & 1.44 & 0.59 to 3.54 & 0.93 & 0.28 to 3.15 & 1.26 & 0.34 to 4.63 \\
\hline $90-50(n=228)$ & 1.54 & 0.97 to 2.47 & 1.24 & 0.80 to 1.93 & 1.27 & 0.75 to 2.13 & 1.74 & 0.97 to 3.10 \\
\hline$\leqslant 50(\mathrm{n}=194)$ & 2.67 & 1.74 to 4.10 & 1.95 & 1.29 to 2.93 & 1.98 & 1.22 to 3.20 & 1.33 & 0.71 to 2.50 \\
\hline
\end{tabular}

^Cholinesterase values missing for 32 cases.

Logistic model adjusted for sex, age, pay status, and race.

Logistic regression models for other diseases of respiratory system did not converge due to few subjects with this diagnosis.

only in men and included pleurisy, pulmonary congestion, and respiratory infection. The logistic regression models for exposure related dose response could not be calculated for this category (other diseases of the respiratory system) due to the small number of subjects with these conditions.

SYMPTOMS, SIGNS, AND ILL DEFINED CONDITIONS General symptoms of dizziness, pyrexia (fever), malaise, and fatigue were more prevalent in cases than controls (OR 1.64, 95\% CI 1.14-2.37, table 3). Although there was no evidence of a higher OR for subjects within the moderate exposure classification or with the greatest mean cholinesterase inhibition, there was an increasing OR found by minimum cholinesterase activity (table 4). Ill defined conditions involving the digestive system (nausea, vomiting, and heartburn) were also found more often in people with potential exposure to chlorpyrifos (OR 1.66, 95\% CI 1.09 to 2.55 ). Table 4 shows that these symptoms were most prevalent among the cases classified as having negligible exposure. There was an inverse dose response for this diagnosis and mean cholinesterase activity. No dose relation was found with minimum cholinesterase activity.

\section{Discussion}

Several people in this study had a mean increase from baseline in their plasma cholinesterase values. This would suggest that their baseline values were already depressed from their true activity. It is possible that these subjects were exposed to an organophosphate at home or that an external factor resulted in lowered plasma cholinesterase values. Although this is a limitation to the sensitivity of the cholinesterase monitoring data it does not indicate that this group had excessive occupational exposure to chlorpyrifos. The positive correlation of the cholinesterase data with the industrial hygiene exposure classifications suggests that there was no systematic bias operating.

The strength of this study is that the exposure was targeted toward chlorpyrifos and not organophosphates as a group. There are, however, several limitations in the study design. Firstly, we could not identify preexisting illnesses because the medical data were collected during the exposure period. Secondly, all medical data were obtained from company medical records, thereby excluding any condition for which an employee was treated externally. Given that all cases knew themselves to be potentially exposed, overre- 
porting is possible. Similarly, because the cases were subjected to monthly cholinesterase tests, they often interacted with the medical department and thereby, may have used the company system more often. Indeed, cases were significantly more likely than the controls to have had a recorded diagnosis of any kind (OR 1.36, $95 \%$ CI 1.08 to 1.70 ). Thirdly, the mean (SD) observation period during which medical data were recorded was longer for the cases (1016 (1269) days) than for the controls (803 (1063) days), offering a greater opportunity for the cases to have illnesses or symptoms abstracted from their company medical records.

These concerns were analysed with the degree of participation in the biennial health surveillance programme and the period of observation. Although $<30 \%$ of the diagnoses were recorded as part of the health surveillance examination, the opportunity to report an illness may have been a function of the frequency with which an employee volunteered for this programme. Although participation after 1982 occurred proportionately more often among cases $(49.2 \%)$ than controls $(46.1 \%)$, stratification by number of surveillance tests did not appreciably change the combined ORs (data not shown). Notably, subjects who did not have a health surveillance examination (since 1982) typically had the highest ORs (compared with those with one or more tests). This indicates that the participants of the health surveillance programme do not tend to use the company medical system more often.

We then investigated whether the period of observation was associated with disease, regardless of exposure. Several of the controls had shorter observation periods than the cases due to leaving work or transfers to an area without company medical facilities. The period of observation was categorised into four levels: $\leqslant 6$ months, $6-18$ months, $18-42$ months, and $\geqslant 42$ months. The four diseases for which logistic regression models could be calculated (diseases of the ear, acute respiratory infections, general ill defined conditions, and ill defined conditions of the digestive system) all showed trends of increased ORs with increasing months of observation (data not shown). These data indicate that the cases, whose mean follow up period was longer than that of the controls, had a greater probability of having a diagnosis abstracted from the company medical records and a higher prevalence of diseases. When duration of observation was controlled in the estimation of the prevalence OR for exposure, exposure was no longer significant for the following diagnostic categories: acute respiratory infections (OR 1.30, 95\% CI 0.93 to 1.82), general ill defined conditions (OR $1.39,95 \%$ CI 0.94 to 2.07 ), and ill defined conditions of the digestive system (OR 1.39, $95 \%$ CI 0.87 to 2.21 ).

The diagnoses relating to the ear, particularly infections and wax build up, are unlikely to be caused by exposure to chlorpyrifos at any level. Likewise, the diagnoses included in the categories of respiratory system disease are primarily of an infectious origin. The ill defined conditions such as dizziness, sleep disturbances, malaise, and fatigue (general ill defined conditions) and nausea, and heartburn (ill defined conditions of the digestive system) are not inconsistent with complaints reported by people with organophosphate poisoning. ${ }^{14}$ However, these subjective symptoms are nonspecific and could be related to shift work, or lifestyle factors such as stress or diet. These symptoms were not dose related with chlorpyrifos exposure or mean plasma cholinesterase inhibition, and therefore do not support a cause and effect relation of these diagnoses and exposure to chlorpyrifos.

When evaluating the minimum cholinesterase activity, highest ORs for three diagnostic categories were found for those with the greatest cholinesterase inhibition. Although the date of this peak inhibition from baseline is available, neither the multiplicity of medical events nor the date of occurrence of the first symptom were recorded by the abstractors. In other words, we cannot determine if the peak exposure temporarily coincided with the recorded diagnosis. The health event could have occurred months or years before or after the peak exposure.

Symptoms of the peripheral nervous system were non-significantly higher among the cases than the controls. Six cases and five controls in this category were diagnosed with carpal tunnel syndrome. This syndrome has been attributed to repetitive physical stress and certain medical conditions but has not been ascribed to chlorpyrifos or organophosphate exposure. Furthermore, proportionately fewer cases than controls reported experiencing tingling in their hands or feet in the health surveillance questionnaire. Thus, there was no apparent increase in peripheral neuropathy among this group of employees potentially exposed to chlorpyrifos.

In conclusion, significantly increased prevalence ORs were identified for five diagnostic categories: disease of the ear and mastoid process; acute respiratory infections; other diseases of the respiratory system; general symptoms, signs, and ill defined conditions; and ill defined conditions of the digestive system. There was no evidence of a dose response by exposure or mean cholinesterase activity. There was a strong relation between diagnosis and longer period of medical observation. Consequently, these data do not support a cause and effect relation between these diagnoses and exposure to chlorpyrifos.

We acknowledge Monica Chau for her programming assistance in identifying the cohort and selecting the matched controls and in identifying the cohort and selecting the matched controls and Rich Nolan for his critical review of an earlier version of the manuscript. We also greatly appreciate the Finney, Charlotte Atton, Elsie McLaren, and Brenda Jammer. This work was supported by The Dow Chemical Company and DowElanco.

1 Hodgson MJ, Block GD, Parkinson DK. Organophosphate poisoning in office workers. F Occup Med 1986;28:434-7. 2 Kaplan JG, Kessler J, Rosenberg N, Pack MD, Schaumburg HH. Sensory neuropathy associated with DURSBAN ${ }^{\mathrm{TM}}$ (chlorpyrifos) exposure. Neurology 1993;43:2193-6.

3 Auito LA, Pavlakis SG, Boxer RA. Life-threatening Auito LA, Pavlakis SG, Boxer RA. Life-threatening
organophosphate-induced delayed polyneuropathy in a organophosphate-induced delayed polyneuropathy in a
child after accidental chlorpyrifos ingestion. $\mathcal{F}$ Pediatr 1993; 122:658-60. 
4 Lotti M, Moretto A, Zoppellari R, Dainese R, Rizzuto N, Barusco G. Inhibition of lymphocytic neuropathy target esterase predicts the development of organophosphateinduced $176-9$.

5 DeSilva HJ, Sanmuganathan PS, Senanayake N. Isolated bilateral recurrent laryngeal nerve paralysis: a delayed complication of organophosphorus poisoning. Hum Exp Toxicol 1994;13:171-3.

6 Ames BG, Brown SK, Rosenberg J, Jackson R, Stratton JW, Quenon SG. Health symptoms and occupational exposure to flea control products among California pet handlers. $A m$ Ind Hyg Assoc F 1989;50:466-72.

7 Yeary RA, Eaton J, Gilmore E, North B, Singell J. A multiyear study of blood cholinesterase activity in urban pesticide applicators. F Toxicol Environ Health 1993;39:1125 .

8 Nolan RJ, Rick DL, Freshour NL, Saunders JH Chlorpyrifos: Pharmacokinetics in human volunteers. Toxicol Appl Pharmacol 1984;73:8-15.
9 Savage EP, Keefe TJ, Mounce LM, Heaton RD, Lewis JA, Burcar PJ. Chronic neurologic sequelae of acute organophosphate pesticide poisoning. Arch Environ Health 1988;

10 Steenland K, Jenkins B, Ames RG, O'Malley M, Chrislip D, Russo J. Chronic neurologic sequelae to organophosphate pesticide poisoning. Am f Public Health 1994;84:731-6.

11 Rosenstock L, Keifer M, Daniell WE, McConnell R, Claypoole K. Chronic central nervous system effects of acute organophosphate pesticide intoxication. Lancet 1991;338: 223-7.

12 Brenner FE, Bond GG, McLaren EA, Greene S, Cook RR. Morbidity among employees engaged in the manufacture or formulation of chlorpyrifos. Br f Ind Med 1989;46:1337.

13 Mantel Haenszel W. Statistical aspects of the analyses of data from retrospective studies of disease $\mathcal{F}$ Natl Cancer Inst 1959;22:719-48.

14 Hayes WJ, Wayland J. Pesticides studied in man. Baltimore, MD: Williams and Wilkins, 1982:301.

\section{Vancouver style}

All manuscripts submitted to Occup Environ Med should conform to the uniform requirements for manuscripts submitted to biomedical journals (known as the Vancouver style.)

Occup Environ Med, together with many other international biomedical journals, has agreed to accept articles prepared in accordance with the Vancouver style. The style (described in full in the $\mathcal{F} A M A[1]$ ) is intended to standardise requirements for authors, and is the same as in this issue.

References should be numbered consecutively in the order in which they are first mentioned in the text by Arabic numerals on the line in square brackets on each occasion the reference is cited (Manson[1] confirmed other reports[2][3][4][5]). In future references to papers submitted to Occup Environ Med should include: the names of all authors if there are seven or less or, if there are more, the first six followed by et al; the title of journal articles or book chapters; the titles of journals abbreviated according to the style of Index Medicus; and the first and final page numbers of the article or chapter. Titles not in Index Medicus should be given in full.

Examples of common forms of references are:

1 International Committee of Medical Journal Editors. Uniform requirements for manuscripts submitted to biomed journals. $\mathscr{F} A M A$ 1993;269:2282-6.

2 Soter NA, Wasserman SI, Austen KF. Cold urticaria: release into the circulation of histmaine and eosinophil chemotactic factor of anaphylaxis during cold challenge. N Engl f Med 1976;294:687-90.

3 Weinstein L, Swartz MN. Pathogenic properties of invading micro-organisms. In: Sodeman WA Jr, Sodeman WA, ing micro-organisms. In: Sodeman WA Jr, Sodeman WA, phia: W B Saunders, 1974:457-72. 